\title{
A Modernização Militar da China e a Distribuição de Poder no Leste Asiático*
}

Arthur Coelho Dornelles Jr.**

\section{Introdução}

Desde o início da década de 1980, a República Popular da China (RPC) vem investindo pesadamente na modernização do Exército de Libertação do Povo (ELP), que é o principal segmento das Forças Armadas chinesas. O ELP é composto pelas Forças Terrestres, Marinha, Força Aérea e pelo Segundo Corpo de Artilharia, responsável pelos mísseis balísticos e de cruzeiro da China, tanto convencionais quanto nucleares (BLASKO, 2006). O ELP está subordinado à Comissão Militar Central (CMC). No entanto, a autoridade sobre as grandes decisões (dispor as tropas no exterior e iniciar uma guerra)

\footnotetext{
* Artigo recebido em 2 de maio de 2013 e aprovado para publicação em $1^{\circ}$ de abril de 2014.

** Doutor em Ciência Política pela Universidade Federal do Rio Grande do Sul (UFRGS) e professor do Departamento de Ciências Sociais da Universidade Federal de Santa Maria (UFSM). E-mail: arthur.coelho@gmail.com.
}

CONTEXTO INTERNACIONAL Rio de Janeiro, vol. 36, nº 1, janeiro/junho 2014, p. 145-170. 
pertence ao Comitê Permanente do Birô Político do Partido Comunista da China (PCC), que é a principal instância decisória do país (SHAMBAUGH, 2002).

O tema deste estudo é o impacto da modernização militar do ELP sobre a distribuição de poder no Leste Asiático. Sobre a distribuição de poder, deve-se ter claro que durante os anos 1980 a balança de poder do Leste Asiático foi multipolar, sendo composta por União Soviética, China e Estados Unidos. Neste período, Moscou conseguia projetar grandes contingentes militares sobre a Sibéria, o Extremo Oriente russo, e a Mongólia, chegando a manter 45 divisões de exército estacionadas nessa região, em função dos temores de uma possível investida chinesa sobre tais territórios. Além disso, até o fim dos anos 1980, os soviéticos conseguiam projetar força naval nos mares do Nordeste e do Sudeste Asiático, por meio de sua grande Frota do Pacífico. Até o fim do referido período, o governo de Moscou conseguiu projetar vastos contingentes sobre o Leste Asiático, porém com um alto custo em função das dificuldades logísticas resultantes da falta de infraestrutura na Sibéria e no Extremo Oriente soviético, bem como do atraso econômico da região. $O$ custo de manutenção dessas forças no Leste Asiático desempenhou um papel significativo na fragilização da economia soviética durante as décadas de 1970 e 1980, levando Moscou a remover suas forças da Mongólia e a retirar o apoio à ocupação vietnamita do Camboja no fim dos anos 1980. Com o término do apoio de Moscou, Hanói teve de buscar uma acomodação com Beijing, o que consolidou a posição chinesa no Sudeste Asiático (ROSS, 2004).

Com o fim da União Soviética em 1991, a Rússia perdeu sua capacidade de projeção de força sobre o Leste Asiático, em virtude das imensas dificuldades econômicas enfrentadas pelo país durante a década de 1990. Em larga medida, estas dificuldades eram resultado da crescente descentralização tributária conduzida em resposta às pressões dos governos provinciais/regionais; da brusca transição para 
uma economia de mercado, associada a imensos problemas de corrupção bastante evidentes no processo de privatização das estatais soviéticas; e do vácuo político que se instaurou em Moscou depois da queda do regime comunista. É importante destacar que o ressurgimento econômico e militar da Rússia na era Putin não significou um retorno ao Leste Asiático, pois Moscou continua enfrentando severas limitações em matéria de projeção de força sobre seu Extremo Oriente, o que em boa medida explica seu papel periférico nas negociações sobre a Coreia do Norte (ROSS, 2004; TODD, 2003; KHANNA, 2008).

Em decorrência do fim da União Soviética, China e Estados Unidos perderam um rival importante no Leste Asiático, o que alterou substancialmente a balança de poder regional, levando-a da multipolaridade à bipolaridade. Ou seja, desde 1991 a China e os Estados Unidos são os únicos polos de poder no Leste Asiático. Contudo, tratava-se de uma balança bipolar relativamente equilibrada porque a RPC era predominante na dimensão terrestre, enquanto os Estados Unidos eram preponderantes na esfera naval. Assim, nenhuma das partes era capaz de contestar a primazia da outra em sua esfera de preponderância, garantindo com isso um considerável equilíbrio militar na região (ROSS, 2004). No entanto, em meados dos anos 1990, a RPC começou a modernizar suas capacidades navais, com o objetivo de reduzir a predominância regional das forças estadunidenses nessa esfera. De modo que, atualmente, o ELP apresenta sólidas capacidades em matéria de combate marítimo, as quais podem representar uma redução da predominância naval das forças estadunidenses no Leste Asiático.

Isso nos leva ao problema de pesquisa, a saber: a China tem condições de enfrentar os Estados Unidos em uma guerra marítima (convencional) e vencer, ou no mínimo degradar seriamente a capacidade combatente das Forças Armadas estadunidenses? Em caso afirmativo, isso indicaria que a bipolaridade do Leste Asiático se tornou de- 
sequilibrada em favor da China, pois ela contaria com a predominância na dimensão terrestre e com um relativo equilíbrio na esfera naval, o que, do ponto de vista analítico, indicaria uma sensível redução do peso dos Estados Unidos na balança do Leste Asiático.

A hipótese adotada é a de que, atualmente, o ELP é capaz de degradar seriamente a capacidade de combate das forças estadunidenses em uma guerra marítima (convencional), por meio de operações de cunho assimétrico, apoiadas em suas capacidades aeronavais, missilísticas e informacionais. Para responder ao problema de pesquisa, serão consideradas as variáveis apresentadas abaixo.

Variável Independente 1 - capacidade de combate do ELP. Indicadores: táticas assimétricas; meios para operações assimétricas.

Variável Independente 2 - capacidade de combate das Forças Armadas estadunidenses. Indicadores: meios militares (apenas o estritamente necessário para efeito de comparação, com o único propósito de determinar as dimensões da força que o ELP deve combater).

Variável Dependente 1 - capacidade de travar uma guerra marítima (convencional) contra os Estados Unidos. Classificada em: 1) capaz de vencer ou degradar seriamente a capacidade de combate das forças estadunidenses no Leste Asiático; ou 2) incapaz de vencer ou mesmo degradar seriamente a capacidade de combate inimiga.

Variável Dependente 2 - distribuição de poder no Leste Asiático (bipolar equilibrada, bipolar desequilibrada).

O método utilizado será o de estudo de caso - comparação focada e estruturada, o que nos permitirá comparar os valores das variáveis independentes dos dois casos em questão. Tal comparação terá um caráter sincrônico, ou seja, considerará os valores das variáveis em um dado momento, apenas (VAN EVERA, 1997). 
$\mathrm{O}$ artigo está dividido em duas seções. A primeira analisa as táticas assimétricas de negação de área e antiacesso (AD/A2), que potencialmente seriam empregadas pela Marinha do Exército de Libertação do Povo (MELP), bem como pela Força Aérea do ELP (FAELP) e pelo Segundo Corpo de Artilharia (SCA) contra os Estados Unidos. Na segunda seção, avalia-se a capacidade chinesa de conduzir tais operações assimétricas contra as forças estadunidenses em uma guerra marítima. ${ }^{1}$

\section{Antiacesso e Negação de Área: Princípios Operacionais}

Os termos antiacesso (A2) e negação de área ( $\mathrm{AD}$, na sigla em inglês) dizem respeito às operações de interdição de acesso das forças navais inimigas, impedindo que penetrem ou avancem sobre determinados corpos de água. Esses termos são normalmente empregados como sinônimos, embora haja algumas tentativas de distinção, como a apresentada pelo Center for Strategic and Budgetary Assessments (CSBA) em relatório de 2010. O referido think tank definiu operações antiacesso como a interdição de acesso das forças navais inimigas às suas bases militares avançadas, como as bases estadunidenses situadas no Japão. Já o conceito de negação de área foi definido pelo órgão como a capacidade de derrotar forças navais móveis. No entanto, empregaremos a definição já consagrada, ou seja, sem diferenciar A2 de AD. É importante esclarecer que se trata de uma terminologia utilizada pelo Pentágono, já que para os chineses esse tipo de operação está compreendida no conceito de Maça Assassina, que postula o emprego de táticas assimétricas diante de um inimigo mais forte (MCDEVITT, 2011; TOL et al., 2010).

O conceito de antiacesso/negação de área é um tipo de operação que envolve o emprego conjunto e combinado entre a MELP, a FAELP e o SCA do ELP. Inicialmente, esse princípio operacional foi adotado 
em função do crescimento do risco de independência por parte de Taiwan durante os anos 1990. Após a crise de 1995/1996, o ELP começou a amadurecer as noções de $\mathrm{A} 2 \mathrm{e} \mathrm{AD}$, largamente inspiradas na experiência soviética.

Durante a Guerra Fria, a União Soviética temia os grupos de batalha estadunidenses, pois estes operavam como plataformas capazes de lançar ataques nucleares por meio de suas aeronaves táticas. Para reduzir essa vulnerabilidade, o governo de Moscou estabeleceu dois perímetros defensivos: o primeiro se estendia até $200 \mathrm{mn}$ da costa soviética, ao passo que o segundo alcançava cerca de $1250 \mathrm{mn}$ da costa. No perímetro interno, a marinha soviética deveria manter o comando do mar, ou seja, deveria ter o domínio pleno e permanente dessa faixa de água. Já no segundo perímetro, a marinha deveria empreender operações de antiacesso/negação de área, no intuito de impedir que as forças estadunidenses se aproximassem da costa soviética, com isso evitando que a costa ficasse ao alcance dos possíveis ataques nucleares das aeronaves estadunidenses. Em meados da década de 1980, a União Soviética chegou a dispor de uma força de 270 submarinos de ataque, 280 grandes embarcações de superfície, e aproximadamente 1.300 aeronaves de emprego naval, divididos entre o Atlântico Norte, o Mediterrâneo Oriental e principalmente o Pacífico, em virtude das necessidades de comando do mar no cinturão interior, e de antiacesso/negação de área no cinturão exterior (MCDEVITT, 2007; 2011).

Para realizar operações de A2/AD, em primeiro lugar, a marinha soviética contava com um sistema de reconhecimento oceânico, assentado sobre uma rede de estações de interceptação eletrônica e "barcos espiões", que deveriam rastrear as emissões eletrônicas das forças navais estadunidenses. Com o passar do tempo, diversos satélites foram incorporados a esse sistema de reconhecimento oceânico, para auxiliar na detecção de sinais infravermelhos e eletrônicos, como os emitidos por radares (MCDEVITT, 2007; 2011). 
Em segundo lugar, os soviéticos dispunham de bombardeiros de longo alcance (como o Backfire) capazes de disparar mísseis de cruzeiro antinavio de longa distância. A tática de combate soviética consistia em enviar dois regimentos (cerca de 40 aeronaves) contra cada grupo de batalha, de modo que uma barragem de mísseis de cruzeiro antinavio pudesse ser disparada contra o inimigo. Em resposta a essa tática, a marinha estadunidense desenvolveu o sistema de defesa antiaérea Aegis (MCDEVITT, 2007; 2011).

Em terceiro lugar, a marinha soviética possuía uma frota de submarinos movidos a propulsão nuclear capazes de interceptar os grupos de batalha estadunidenses no perímetro exterior, com o objetivo de impedir seu avanço sobre o perímetro interior. Os submarinos eram vetorados por terra, com base nas informações levantadas pelo sistema de reconhecimento oceânico. Além disso, tais submarinos eram equipados com uma grande quantidade de mísseis de cruzeiro antinavio, representando uma ameaça bastante séria à marinha estadunidense $^{2}$ (MCDEVITT, 2007; 2011).

\section{Meios Militares para a Condução de Operações de A2/AD}

Com base na experiência soviética mencionada anteriormente, o ELP estruturou suas operações de A2/AD. Por essa razão, o primeiro componente desse tipo de operações consiste na capacidade de vigilância e reconhecimento oceânico. Para isso, o ELP conta com cerca de trinta satélites, somando-se os de uso civil e os de emprego militar. Entre os de uso militar, o ELP dispõe dos satélites da série Yaogan, que atualmente conta com quinze satélites (dezessete células). Desse total, oito utilizam Radares de Abertura Sintética (SAR, na sigla em inglês), que possibilitam a obtenção de imagens em qualquer clima, independentemente da quantidade de luz disponível. A resolução média desses dispositivos é de $5 \mathrm{~m}$. A série Yaogan ainda possui oito 
satélites equipados com sensores eletro-ópticos (EO), que permitem o recolhimento de imagens no espectro da luz visível. Sua resolução média é de $1 \mathrm{~m}$. Das dezessete células, apenas uma possui sensores de inteligência eletrônica (ELINT). Ela tem capacidade de coleta de sinais eletrônicos, tais como os emitidos pelos radares das embarcações ou aeronaves. O ELP possui também os satélites da série Ziyuan (2A, 2B, 2C, 3), todos equipados com sensores multiespectrais infravermelhos (MEI), com uma resolução entre 2m e 3m (CEPIK, 2011; ERICKSON, 2011; STOKES, 2012).

A China ainda dispõe de vários satélites de uso civil que podem ser empregados em caso de conflito armado. Entres eles, estão o Haiyang 2B (EO), o Haiyang 3 (SAR), bem como o Huanjing 1A (MEI) e o Huanjing 1B, dotado de sensores hiperespectrais infravermelhos. A resolução dos dois últimos dispositivos é de aproximadamente 30m. A RPC também conta com os satélites Shiyan 1, 2 e 3 (todos EO), que possuem resolução entre $5 \mathrm{~m}$ e $10 \mathrm{~m}$, e com os dois dispositivos da série Fengyun (1D e 3A), ambos equipados com sensores de micro-ondas, infravermelhos e espectro visível da luz. Com isso, percebe-se que o ELP pode ter à sua disposição um número significativo de satélites de vigilância e sensoriamento (30 células), dotados de diversos tipos de sensores que são, em média, bastante capazes (HAGT; DURNIN, 2009; ERICKSON, 2011; STOKES, 2012).

Contudo, Hagt e Durnin (2009, p. 100-102) conduziram uma simulação de 72hs com 22 satélites de vigilância e sensoriamento disponíveis ao ELP, e constataram que o tempo médio entre as passadas dos satélites era de 45 minutos sobre a mesma faixa do globo, com 14 passadas diárias no total. A simulação, no entanto, apresentou lapsos temporais muito significativos entre algumas passagens, implicando em nove hiatos de aproximadamente duas horas, ou seja, duas horas sem a cobertura de satélites. ${ }^{4}$

Entretanto, com oito satélites além dos 22 considerados na simulação, o ELP teria um ganho de $36,4 \%$ em sua capacidade de inteligên- 
cia, vigilância e reconhecimento (ISR, na sigla em inglês) baseada no espaço sideral. Com isso, pode-se supor que seria reduzido o tempo entre as passadas para aproximadamente 29 minutos, aumentando para 19 o número total de passagens sobre a mesma faixa do globo. ${ }^{5}$ Da mesma forma, os nove hiatos de 120 minutos seriam diminuídos para cerca de 77 minutos. Embora isso indique claramente um avanço substancial na capacidade de recolhimento de informação via satélite, percebe-se que a China ainda enfrenta limitações expressivas neste campo, pois em cerca de trinta minutos um porta-aviões pode se deslocar aproximadamente $32 \mathrm{~km}$ (a $35 \mathrm{kts}$ ), ou seja, é capaz de se afastar significativamente de seu ponto de identificação, dificultando consideravelmente seu rastreamento e, consequentemente, seu engajamento.

Essa deficiência tende a ser bastante reduzida com o emprego do Radar Além do Horizonte (OTH-R, na sigla em inglês) de Superfície de Onda, disponível ao ELP desde o fim dos anos 1960. Ele é capaz de localizar grandes embarcações de superfície e aeronaves voando a baixas altitudes dentro de um raio de 300 ou $400 \mathrm{~km}$, o que é suficiente para vigiar a costa, mas insuficiente para a vigilância oceânica. Para sanar esse problema, o ELP vem desde 2003 empregando o sistema de pulso Doppler no referido radar, aumentando drasticamente seu alcance, hoje estimado em cerca de $3000 \mathrm{~km}$, o que permite o reconhecimento de vastas porções do Pacífico Ocidental. Se esse radar for empregado em conjunto com os satélites mencionados acima, então provavelmente o ELP teria condições de localizar, rastrear e engajar os alvos a grandes distâncias da costa chinesa, podendo, com isso, acertar as embarcações estadunidenses com mísseis de cruzeiro lançados por submarinos ou por aeronaves (LIU, 2007).

Caso a combinação das duas tecnologias não seja suficiente, o ELP ainda poderia empregar seus veículos aéreos não tripulados (VANTs) para auxiliar no recolhimento de informações sobre a localização das embarcações inimigas. Para esse tipo de missão, seria es- 
pecialmente útil o Xianglong, que atualmente é o maior VANT empregado pelo ELP. Essa aeronave possui um alcance de aproximadamente $7500 \mathrm{~km}$, ou seja, é perfeitamente capaz de atuar dentro da segunda corrente de ilhas. Contudo, é incapaz de voar a altitudes maiores do que o alcance dos sistemas de defesa antiaérea dos grupos de batalha estadunidenses, o que representa um risco considerável para a aeronave e, consequentemente, limita substancialmente suas chances de rastrear a frota inimiga (embora não impeça a localização momentânea).

Para suprir as eventuais lacunas de ISR deixadas pelas três tecnologias mencionadas anteriormente, o ELP ainda poderia contar com informações fornecidas por sua marinha mercante, bem como pelos barcos de pesca chineses (HAGT; DURNIN, 2009).

Deste modo, a China poderia cumprir a segunda etapa das operações de A2/AD, ou seja, barrar as forças navais e aéreas do inimigo. Para tanto, o ELP teria de ser capaz de atingir a marinha estadunidense com grande quantidade de mísseis antinavio. Contudo, o ELP ainda não dispõe de mísseis de cruzeiro antinavio de longa distância capazes de serem lançados por aeronaves. ${ }^{6}$ Além disso, a China não possui bombardeiros de alcance similar aos empregados pelos soviéticos durante a Guerra Fria, o que limita o alcance das operações de A2/AD chinesas.

Porém, com o objetivo de reduzir esse problema, a China vem aperfeiçoando seus mísseis balísticos antinavio, os quais têm alcance para atingir os grupos de batalha estadunidenses a grandes distâncias. Normalmente, mísseis balísticos não seriam eficazes contra alvos móveis, pois, uma vez disparados, não é possível alterar sua trajetória. No entanto, os chineses estão desenvolvendo a capacidade de guiagem de mísseis balísticos após a reentrada na atmosfera, o que lhes permitiria corrigir a rota e acertar alvos móveis, tais como porta-aviões ou grandes embarcações de superfície. Para se ter uma 
ideia, mísseis como o DF-21 (CSS-5) possuem um alcance de 1336 mn $(2471 \mathrm{~km})$, o que cobre a maior parte da segunda corrente de ilhas. De acordo com Stokes (2009), essa tecnologia ainda não estaria plenamente operacional, mas já estaria em fase avançada de testes, devendo entrar em operação antes de 2015 (TOL et al., 2010; U.S. DEPARTMENT OF DEFENSE, 2011; MCDEVITT, 2011).

Entretanto, o ELP não conta apenas com este trunfo para negar acesso à marinha estadunidense, pois a FAELP possui diversos bombardeiros de alcance intermediário e vários caças-bombardeiros com grande autonomia. Entre eles estão um regimento (cerca de vinte aeronaves) do bombardeiro $\mathrm{B} 6 \mathrm{H}$, um regimento do caça-bombardeiro FB-7, aproximadamente setenta bombardeiros JH-7, e cerca de setenta aeronaves do modelo Su-30MKK, que são caças multifunção de procedência russa, capazes de alcançar cerca de $1150 \mathrm{mn}$ da costa chinesa. A aviação da MELP ainda dispõe de quatro regimentos do $\mathrm{JH}-7$, aproximadamente quarenta bombardeiros H-6D, bem como um regimento do Su-30MK2, armado com o míssil de cruzeiro supersônico Kh-31 (AS-17A) ${ }^{7}$ (IISS, 2011).

Com isso, tem-se um total aproximado de 320 aeronaves, ou cerca de quinze regimentos, todos capazes de lançar mísseis de cruzeiro antinavio. Seguindo a métrica soviética, dois regimentos por grupo de batalha estadunidense ${ }^{8}$ seria o suficiente para barrá-lo ou derrotá-lo. Contudo, os soviéticos contavam com mísseis de cruzeiro de longo alcance, do qual a China ainda não dispõe. Isso permitia às aeronaves de Moscou disparar de grande distância, sem entrar no perímetro das defesas antiaéreas da marinha estadunidense. No caso chinês, as aeronaves teriam de entrar no perímetro defensivo do inimigo para dispararem seus mísseis, e isso implicaria baixas potencialmente substanciais. Em vista dessa limitação, avalia-se que a métrica ideal para o ELP seria de três regimentos por grupo de batalha. Com isso, a China poderia combater até cinco grupos de batalha inimigos, mas as re- 
feridas aeronaves teriam maior efetividade se apoiadas pelos submarinos da MELP (MCDEVITT, 2011; IISS, 2011; CLIFF et al., 2007).

A força de submarino chinesa é o terceiro componente de suas operações de A2/AD, e é neste ponto que a MELP desempenharia seu principal papel em todo o esforço de negação de área. A China possui sessenta submarinos de ataque movidos a propulsão diesel-elétrica (SSK). Desse total, 32 são modernos e 28 são relativamente antiquados, pois apresentam assinatura sonora elevada para a categoria (SSK), além de serem incapazes de lançar mísseis de cruzeiro. A MELP ainda conta com seis submarinos movidos a propulsão nuclear (SSN), sendo todos considerados embarcações modernas, embora possuam diferenças significativas em matéria de furtividade. Com isso, tem-se um total de 66 embarcações, sendo 38 plenamente capazes e 28 apenas limitadamente. De acordo com avaliações do ELP, o raio de ação de um F/A-18 é de aproximadamente 1200 mn, ou seja, se os chineses desejam evitar uma batalha aérea sobre o Estreito de Taiwan, ou mesmo sobre a costa da RPC, então provavelmente iriam tentar barrar o avanço dos grupos de batalha estadunidenses a uma distância superior ao raio de ação da aeronave de combate encontrada nos porta-aviões inimigos. Deste modo, é provável que a linha de negação de área fique entre 1200 e 1400 mn da costa chinesa, em outras palavras, seria nessa faixa que os submarinos da MELP deveriam ser posicionados.

Segundo McDevitt (2007), seriam necessários cerca de seis submarinos para combater cada grupo de batalha. Se assumirmos que os Estados Unidos despachariam três ou quatro porta-aviões com escolta para as imediações de Taiwan (caso o combate seja pela ilha), então a MELP teria de dispor entre dezoito e 24 submarinos. Pode-se estimar que, para manter um submarino diesel-elétrico em combate a grandes distâncias (cerca de 1200 mn), é preciso dispor de no mínimo mais dois, ou seja, um no porto, sendo reabastecido com combustível, provisões, armamento etc., outro dirigindo-se ao campo de ba- 
talha, e outro combatendo na linha de frente. Assim, para sustentar uma operação de $\mathrm{A} 2 / \mathrm{AD}$ contra três ou quatro grupos de batalha, a MELP precisaria de algo entre 54 e 72 submarinos.

Em suma, se tivesse de enfrentar três grupos de batalha, a China teria a quantidade de submarinos necessária; mas, se fossem quatro porta-aviões com suas escoltas, então os submarinos chineses teriam de permanecer mais tempo na linha de frente, e teriam de cumprir um cronograma de revezamento bastante apertado, demandando um esforço logístico imenso e especialmente arriscado para os 28 submarinos antigos (MCDEVITT, 2011; 2007; IISS, 2011; CLIFF et al., 2007).

Considerando-se a capacidade aérea do ELP e as dimensões e características da frota de submarinos da MELP, percebe-se que a China teria condições de enfrentar com boas chances de sucesso até três grupos de batalha; mas, contra quatro, as chances se reduziriam sensivelmente. Claro, desde que o reconhecimento oceânico seja capaz de localizar e rastrear as embarcações inimigas, e que o centro de comando e controle seja capaz de gerir as dimensões aérea, naval, informacional e logística do conflito, o que não é uma tarefa trivial. Contudo, essa avaliação poderia mudar significativamente se o sistema de guiagem de mísseis balísticos antinavio já estivesse em operação.

Evidentemente, essas três dimensões das operações de A2/AD seriam precedidas por ataques ao sistema de $\mathrm{C}_{4} \mathrm{ISR}^{9}$ das forças estadunidenses localizadas no teatro de operações. Inicialmente, a rede de computadores inimiga seria atacada pelo ELP por meio de guerra cibernética, isto é, ataques de vírus, poluição de informação, coleta de informações etc. Essa etapa seria coordenada com ataques aos principais nós móveis da cadeia de comando, controle e comunicação das forças estadunidenses, ou seja, tais ataques seriam dirigidos contra os satélites inimigos, bem como seus porta-aviões e suas aeronaves de AWACS. ${ }^{10}$ 
Os ataques aos satélites seriam realizados com míssil antissatélite, como o testado com sucesso pela China em 2007, ou com armas de energia direta $^{11}$ (TELLIS, 2007). Já os ataques aos porta-aviões, provavelmente, seriam empreendidos com pulsos eletromagnéticos não nucleares, capazes de sobrecarregar os equipamentos eletrônicos estadunidenses (sensores de rastreio, sistemas de comunicação, sistemas de defesa etc.), neutralizando-os temporariamente ou permanentemente, dependendo da intensidade do pulso. É neste momento que a frota seria atacada por uma barragem de mísseis antinavio. Os mísseis seriam disparados por submarinos, grandes embarcações de superfície, bem como pelas aeronaves de combate baseadas em solo, como mencionado anteriormente. Para garantir o sucesso de sua operação, o ELP contaria com os fatores iniciativa e surpresa. Os chineses entendem que, se chegassem ao ponto de iniciar a ofensiva no plano tático, é porque o inimigo já teria iniciado a guerra no nível estratégico, ou seja, trata-se de uma das características do princípio estratégico de "defesa ativa" (CLIFF et al., 2007).

Concomitantemente com essa primeira etapa, provavelmente o ELP atacaria as bases aéreas estadunidenses situadas na região. Tais ataques seriam realizados com mísseis balísticos de curto alcance, ${ }^{12}$ uma vez que esses mísseis têm condições de alcançar Kadena (Okinawa/Japão), Yokota (Japão), Osan e Kunsan (ambas na Coreia do Sul), que são as principais bases aéreas dos Estados Unidos na região. Dessas bases, a mais próxima de Taiwan é a de Kadena, situada a apenas $460 \mathrm{mn}$ da referida ilha, e a aproximadamente $350 \mathrm{mn}$ da costa chinesa (CLIFF et al., 2007).

Cabe indagar se a RPC poderia atacar as bases aéreas dos Estados Unidos de modo a anular ou degradar substancialmente sua capacidade aérea na região. Sem isso, as aeronaves chinesas se encontrariam em desvantagem durante sua investida sobre os grupos de batalha estadunidenses, pois o comando do ar seria fortemente contestado pela Força Aérea dos Estados Unidos (USAF, na sigla em inglês). 
Da mesma forma, as embarcações de superfície da MELP estariam altamente expostas às investidas aéreas do inimigo.

Consideremos o caso de Kadena, tanto por sua proximidade com Taiwan quanto por ser a maior base aérea da região, contando com as duas pistas de decolagem mais longas à disposição da USAF no Nordeste Asiático (3700 m). Além disso, Kadena é uma base afastada dos grandes centros populacionais, diferente de Yokota, Osan e Kunsan, o que, do ponto de vista político, é bastante relevante, pois provavelmente a China tentará evitar que o Japão e/ou a Coreia do Sul entrem na guerra ao lado dos Estados Unidos.

Segundo Hoyler (2010), os mísseis DF-15 são bastante precisos atualmente, ${ }^{13}$ de modo que apenas doze ogivas unitárias poderiam atingir as duas pistas de Kadena, fragmentando-as em trechos curtos o suficiente para impedir a decolagem das aeronaves da USAF. Este seria o primeiro passo em um ataque a uma base aérea, para impedir que os aviões decolassem após o início da ofensiva. O segundo passo consistiria em atacar as aeronaves desprotegidas da base, ou seja, estacionadas fora de abrigos reforçados. Como a base de Kadena possui apenas quinze desses abrigos, seria possível proteger no máximo trinta aviões de caça (considerando dois por abrigo). Os demais ficariam expostos no pátio da base, juntamente com as grandes aeronaves de AWACS (E-3), de vigilância (P-3) e de carga. Estima-se que com cerca de quarenta DF-15 armados com submunições seja possível destruir ou avariar seriamente $75 \%$ das aeronaves estacionadas em Kadena. ${ }^{14}$ Considerando-se que, segundo Stillion e Orletsky (1999, p. 14), uma ogiva de 500 kg é capaz de transportar 825 submunições que provocam um raio de destruição de aproximadamente $300 \mathrm{~m}$, essa estimativa se mostra bastante razoável. Para aumentar a efetividade de seus DF-15, a China ainda poderia empregar mísseis antirradiação contra os radares do sistema de defesa Patriot (PAC-3 ABM), com isso degradando a capacidade de defesa antiaérea do inimigo. 
Contudo, ainda assim o PAC-3 seria um adversário formidável para os DF-15 chineses, uma vez que esse sistema possui uma taxa de acerto de $91 \%$ (disparando dois mísseis contra o míssil inimigo). De acordo com Hoyler (2010), oficialmente o inventário de Kadena conta com 512 mísseis do sistema PAC-3; porém, no final de 2010, os Estados Unidos dispunham de um total de 791, o que torna o número oficial de Kadena bastante exagerado, especialmente se levarmos em consideração a ameaça representada pelo Irã, o que certamente demandaria várias unidades desse sistema para proteger as bases estadunidenses localizadas no Golfo Pérsico. É mais provável que a referida base aérea disponha de apenas 250 ou 300 mísseis do sistema PAC-3. Entretanto, utilizaremos aqui o dado oficial.

Sendo assim, se assumirmos plena capacidade de aviso antecipado e detecção por parte dos sensores da base estadunidense, então a defesa antiaérea de Kadena poderia engajar até 256 DF-15 e destruir aproximadamente 233 alvos (9\% de erro). Percebe-se que, com 285 DF-15, a base aérea de Kadena seria duramente atingida pelas 52 ogivas que sobreviveriam à sua defesa antiaérea. ${ }^{15} \mathrm{O}$ número sugerido é certamente elevado, mas, de acordo com o U.S. Department of Defense (2010, p. 66), a China possui entre 350 e 400 DF-15, o que indica que o ELP poderia atacar a base aérea de Kadena com sucesso, anulando ou degradando pesadamente sua capacidade operacional. Tal resultado limitaria seriamente as possibilidades de operação da USAF no Nordeste Asiático e, potencialmente, em todo o Pacífico Ocidental por vários meses.

Em resumo, pelo exposto até aqui, percebe-se que o ELP teria boas chances de vencer até três grupos de batalha estadunidenses e de anular a capacidade operacional da principal base aérea dos Estados Unidos no Leste Asiático. Isso nos leva a concluir que o ELP teria condições de, no mínimo, degradar seriamente a capacidade de combate aéreo e naval dos Estados Unidos na região. Além disso, a tendência nos próximos anos é de que as capacidades chinesas sejam sensivel- 
mente ampliadas, na medida em que se tornem operacionais os mísseis balísticos antinavio do ELP, e que sua capacidade de ISR baseada no espaço seja aprimorada.

Porém, o desenvolvimento de tais capacidades por parte da China e o enfraquecimento relativo dos Estados Unidos desde 2001 acentuou o dilema de segurança no nível regional, levando diversos países do Leste Asiático a buscarem algum tipo de contramedida ao crescimento da capacidade de combate naval do ELP, seja aliando-se ainda mais claramente aos Estados Unidos, seja realizando esforços próprios de modernização naval. Da mesma forma, os Estados Unidos passaram a desenvolver contramedidas às novas capacidades do ELP, e tal resposta pode conduzir os dois atores a uma acirrada corrida armamentista. Entretanto, esse é um assunto para outro artigo.

\section{Considerações Finais}

Em primeiro lugar, conclui-se que, ao contrário do que postulam os defensores da unipolaridade (BROOKS; WOHLFORTH, 2008; WOHLFORTH, 1999; WOHLFORTH; BROOKS, 2002), está havendo um visível esforço de contrabalanço militar. Entretanto, os referidos autores são incapazes de perceber tais esforços em função de sua predileção por dados agregados (gastos em defesa; investimentos em pesquisa $\&$ desenvolvimento militar etc.), e também porque esse balanceamento está sendo conduzido no nível regional, em vez do global, que é o foco dos defensores da unipolaridade.

É evidente que somente os Estados Unidos têm condições de intervir militarmente em qualquer região do mundo, equilibrando ou desequilibrando as balanças regionais. Contudo, o fato de não haver outro Estado no globo buscando esse grau de projeção de força não significa que não esteja havendo contrabalanço. Na verdade, significa apenas que as grandes potências (atores com alcance militar essencialmente regional e inter-regional) atuais enfrentam as principais amea- 
ças nas suas regiões, logo, não encontram necessidade de investir em projeção de força em nível global. Em outras palavras, diante de tal critério maximalista, é compreensível a posição dos defensores da unipolaridade. Entretanto, sob qualquer critério menos extremo, esta posição se torna completamente insustentável empiricamente, em especial à luz dos inventários militares e seus meios de emprego.

Além disso, a constatação de um esforço tradicional (militar) de contrabalanço também contraria a previsão dos defensores do conceito de "balanceamento suave" (PAUL, 2005; PAPE, 2005), os quais alegam que a unipolaridade tem levado os Estados a buscarem formas não tradicionais de contrabalanço, uma vez que, segundo os autores, o balanceamento militar seria muito arriscado e muito caro nesta configuração de poder. O "balanceamento suave" seria observado em esforços estatais, tanto individuais quanto coletivos, no sentido de obstaculizar diplomaticamente determinadas iniciativas dos Estados Unidos, de modo a elevar o custo de operação e sustentação da unipolaridade. Em suma, os defensores do "balanceamento suave" aceitam acriticamente a ideia de unipolaridade, uma vez que suas análises também estão concentradas em dados agregados.

Em segundo lugar, o esforço de balanceamento no Leste Asiático levou à configuração de uma balança regional bipolar desequilibrada em favor da China, em que a RPC é preponderante na dimensão terrestre, e atualmente se apresenta como um adversário à altura dos Estados Unidos na esfera naval, pois o ELP é capaz de travar uma guerra marítima (convencional) contra as forças estadunidenses no Leste Asiático, com grandes chances de degradar seriamente a capacidade de combate dos Estados Unidos na região e forçar o encerramento das hostilidades, mantendo seus interesses intactos.

Embora as conclusões apresentadas aqui tenham como objeto o nível regional, elas possuem implicações no nível global, pois, na medida em que se fortalece a posição chinesa na balança regional, maior é a 
tendência de os Estados Unidos projetarem (de maneira mais ou menos realista) pretensões semelhantes de Beijing na balança global. Em outras palavras, é esse efeito prospectivo que tem levado o governo estadunidense a realizar ações de "cercamento" da China pela Ásia Central, Sul da Ásia e Sudeste Asiático desde 2002.

Essas conclusões corroboram indiretamente a posição de Waltz (1993; 2000), que postula a realização de esforços contrabalançantes no atual sistema internacional, no intuito de levar a distribuição de poder global novamente ao equilíbrio diante do que teria sido uma concentração desproporcional de poder nas mãos de Washington desde 1991. Contudo, o que significará, no século XXI, a distribuição de poder no nível global? Será necessário para as grandes potências (Rússia, China e, talvez, Europa) disporem de capacidade de projeção global de força para obrigar os Estados Unidos a revisarem as estruturas políticas e econômicas de governança levando em conta os interesses e valores dos demais polos de poder?

Acredita-se que não. Em primeiro lugar, porque os britânicos desenvolveram tal capacidade no século XIX por disporem dos recursos econômicos para isso, e porque se consideravam seguros em função de sua condição insular, bem como do equilíbrio de poder sustentado por eles no continente europeu. Da mesma forma, os Estados Unidos desenvolveram a capacidade de projeção de força em nível global porque, além de possuírem as condições econômicas necessárias, não enfrentam rivais no continente americano desde a guerra de 1898 contra a Espanha. Em outras palavras, nos dois casos houve uma confluência de fatores econômicos, políticos e geográficos que levou ao desenvolvimento de tais capacidades. Esta confluência de fatores está ausente na atualidade, uma vez que as grandes potências (China, Rússia e, talvez, União Europeia) enfrentam as principais ameaças em suas próprias regiões.

Em segundo lugar, porque diante da crescente impossibilidade estadunidense de sustentar seus elevados gastos militares, e das dificul- 
dades associadas a qualquer esforço significativo de redução de tais gastos, os Estados Unidos tendem a perder a condição de superpotência (atores com capacidade de projeção de força em nível global), tornando-se apenas uma grande potência nas próximas duas ou três décadas (DORNELLES, 2012). Esse desdobramento, tendencialmente, levará ao arrefecimento do dilema de segurança entre as grandes potências, uma vez que as dinâmicas de segurança regional tenderão a se tornar relativamente isoladas, devido à ausência de grandes potências extrarregionais interferindo no "quintal" de seus pares. Com isso, os Estados dominantes terão ainda menos incentivos para investir em projeção global de força.

Entretanto, antes de chegar a esse sistema internacional sem superpotências, os Estados Unidos terão de administrar seu declínio (tanto relativo quanto absoluto) e, como Copeland (2000) demonstrou, são os Estados predominantes que, quando em declínio pronunciado, tendem a iniciar a guerra contra seus rivais em ascensão, antes que estes igualem seu poder. Em síntese, a paz e a estabilidade do Leste Asiático dependerão, sobretudo, de como os Estados Unidos lidarão com o fim de sua condição de superpotência.

\section{Notas}

1. Neste artigo, utilizam-se, predominantemente, fontes ocidentais sobre as capacidades militares chinesas. Privilegiaram-se as pesquisas dos principais acadêmicos estadunidenses e britânicos dedicados ao estudo de tais capacidades. O autor está ciente das limitações decorrentes deste ponto, mas entende que isso não inviabiliza os resultados do presente estudo.

2. Pode-se notar que a noção de primeira e segunda corrente de ilhas empregada por Liu Huaqing guarda bastante semelhança com a estratégia defensiva de Moscou, que dividia em dois perímetros seu entorno marítimo. Esta semelhança não é casual, pois em meados dos anos 1980 Liu estudou na União Soviética, precisamente na Academia Naval de Voroshilov, quando o almirante Sergei 


\section{A Modernização Militar da China e a Distribuição de Poder no Leste Asiático}

Gorshkov era um instrutor nesta instituição. Gorshkov foi um dos maiores estrategistas navais da União Soviética, chegando ao posto de comandante da Marinha no fim dos anos 1980. Pelo que se percebe, a obra de Gorshkov e suas ideias desempenharam um papel-chave na concepção estratégica de Liu, e consequentemente na estratégia naval chinesa (COLE, 2001).

3. Segundo Hagt e Durnin (2009) e Stokes (2012), os satélites da série Yaogan são dispositivos militares. Contudo, autores como Erickson (2011) o apresentam como de uso civil.

4. Isto considerando um nadir de 60 graus, ou seja, considerando uma amplitude de visão bastante elevada para os satélites chineses, uma vez que os satélites militares possuem um nadir entre 45 e 60 graus; porém, os civis ficam em uma faixa entre 35 e 45 graus, salvo raras exceções, como a série Haiyang (STOKES, 2012).

5. Evidentemente, o cálculo apresentado aqui é apenas uma simplificação aproximativa, que objetiva ilustrar o (provável) potencial do ELP em matéria de ISR baseado no espaço.

6. Segundo o U.S. Department of Defense (2010), este tipo de míssil de cruzeiro está sendo desenvolvido pela China, mas não há previsão para o início de seu emprego.

7. O AS-17A é um míssil ar-superfície antirradiação e, como tal, criado para derrubar os radares de busca do inimigo e seus radares de controle de fogo, com isso anulando a capacidade de defesa antiaérea do alvo. Seu alcance é de aproximadamente $110 \mathrm{~km}$.

8. Os Estados Unidos possuem atualmente onze grupos de batalha (também denominados grupos de ataque). Um grupo de batalha da Marinha dos Estados Unidos, normalmente, é composto por um porta-aviões (com cerca de setenta aeronaves), um ou dois cruzadores (equipados com mísseis de cruzeiro de longo alcance), três ou quatro destróieres (para defesa antiaérea e para combate antissubmarino, mas dispondo também de mísseis de cruzeiro de longo alcance), três fragatas, um ou dois submarinos movidos a propulsão nuclear, e diversas embarcações de apoio e logística, tais como navios tanque, navios de suprimentos etc. (IISS, 2011).

9. Command, Control, Communications, Computers, Intelligence, Surveillance, and Reconnaissance (Comando, Controle, Comunicação, Computação, Inteligência, Vigilância e Reconhecimento).

10. Airborne Warning Control System (Sistema de Controle e Alerta Aéreo). 
11. Em matéria de armas de energia direta, as principais opções disponíveis atualmente ao ELP são os lasers baseados em terra. Com lasers de alta potência, é possível causar dano estrutural aos satélites inimigos, levando à sua desativação permanente. Já os lasers de baixa potência podem ser empregados para sobrecarregar os sensores dos satélites estadunidenses, desabilitando-os temporariamente (TELLIS, 2007).

12. Para isso, seriam utilizados os DF-15 (CCS-6), que possuem um alcance entre 370 e 500 mn dependendo da versão (CLIFF et al., 2007).

13. $\mathrm{O}$ autor refere-se aos DF-15A, que possuem um CEP de 10 a $30 \mathrm{~m}$, ao passo que a versão DF-15 apresenta um CEP de aproximadamente 300 m (U.S. DEPARTMENT OF DEFENSE, 2010).

14. A elevada margem de erro (300 m) da primeira versão do DF-15 não representaria uma dificuldade substancial, desde que esta versão menos precisa fosse equipada com as submunições e direcionada à zona de estacionamento das aeronaves. Já a versão mais precisa (e mais escassa) poderia ser destinada às pistas da base aérea.

15. O cálculo é o seguinte: $285 \mathrm{DF}-15$ lançados -233 interceptados $=52$ ogivas sobre Kadena, sendo quarenta para destruir as aeronaves e doze para destruir as pistas.

\section{Referências} Bibliográficas

BLASKO, Dennis J. The Chinese Army Today. Londres: Routledge, 2006.

BROOKS, Stephen; WOHLFORTH, William. World out of Balance: International Relations and the Challenge of American Primacy. Princeton: Princeton University Press, 2008.

CEPIK, Marco. A política da cooperação espacial chinesa: contexto estratégico e alcance internacional. Revista de Sociologia e Política, v. 19, n. suplementar, p. 77-100, 2011.

CLIFF, Roger; BURLES, Mark; CHASE, Michael S.; EATON, Derek; POLL-PETER, Kevin L. Entering the Dragon's Lair: Chinese Antiaccess 
Strategies and their Implications for the United States. Santa Mônica: RAND, 2007.

COLE, Bernard. The Great Wall at Sea: China's Navy Enters the Twenty-First Century. Annapolis: U.S Naval Institute Press, 2001.

COPELAND, Dale. The Origins of Major War. Ithaca: Cornell University Press, 2000.

DORNELLES, Arthur. China e Estados Unidos na balança de poder do Leste Asiático: comparações econômicas e militares. Tese (Doutorado em Ciência Política) - Universidade Federal do Rio Grande do Sul, Porto Alegre, 2012.

ERICKSON, Andrew. Satellites Support Growing PLA Maritime Monitoring and Targeting Capabilities. China Brief, Carnegie Endowment for International Peace, v. 11, n. 3, 2011.

HAGT, Eric; DURNIN, Matthew. China's Antiship Ballistic Missile: Developments and Missing Links. Naval War College Review, v. 62, n. 4, p. 87-115, 2009.

HOYLER, Marshall. China's "Antiaccess" Ballistic Missiles and U.S. Active Defense. Naval War College Review, v. 65, n. 4, p. 84-105, 2010.

IISS - International Institute for Strategic Studies. Military Balance. Londres: International Institute of Strategic Studies, 2011.

KHANNA, Parag. O segundo mundo. São Paulo: Intrínseca, 2008.

LIU, Bin-Yi. HF Over-the-Horizon Radar System Performance Analysis. Monterey: Naval Post-Graduate School, 2007.

MCDEVITT, Michael. The Strategic and Operational Context Driving PLA Navy Building. In: KAMPHAUSEN, R.; SCOBELL, A. Right Sizing the People's Liberation Army: Exploring the Contours of China's Military. Carlisle: Strategic Studies Institute, U.S. Army War College, 2007. p. 481-522.

- The PLA Navy's Antiaccess Role in a Taiwan Contigency. In: SAUNDERS, P. et al. The Chinese Navy: Expanding Capabilities, Evolving Roles. Washington: National University Press, 2011. p. 191-214.

PAPE, Robert. Soft Balancing against the United States. International Security, v. 30, n. 1, p. 7-45, 2005. 
PAUL, T. V. Soft Balancing in the Age of U.S Primacy. International Security, v. 30, n. 1, p. 46-71, 2005.

ROSS, Robert S. Bipolarity and Balancing in East Asia. In: PAUL, T. V.; WIRTZ, J.; FORTMANN, M. Balance of Power: Theory and Practice in the $21^{\text {st }}$ Century. Stanford: Stanford University Press, 2004. p. 267-304.

SHAMBAUGH, David. The Pinnacle of the Pyramid: The Central Military Commission. In: MULVENON, J. C.; YANG, A. N. D. (Ed.). The People's Liberation Army as Organization: Reference Volume v 1.0. Santa Monica: RAND Corporation, 2002. p. 95-121.

STILLION, John; Orletsky, David. Airbase Vulnerability to Conventional Cruise-missile and Ballistic-missile Attacks: Technology, Scenarios, and USAF Respondes. Santa Monica: Rand Corporation, 1999.

STOKES, Mark. China's Evolving Conventional Strategic Strike Capability: The Anti-ship Ballistic Missile Challenge to U.S. Maritime Operations in the Western Pacific and Beyond. Project 2049 Institute. September, 14, 2009.

China's Evolving Space Capabilities: Implications for U.S. Interests. The U.S. - China Economic and Security Review Commission. April, 26, 2012.

TELLIS, Ashley. China's Military Space Strategy. Survival, v. 49, n. 3, p. 41-72, 2007.

TODD, Emmanuel. Depois do Império. São Paulo: Record, 2003.

TOL, Jan van; GUNZINGER, Mark; KREPINEVICH, Andrew F.; THOMAS, Jim. AirSea Battle: A Point-of-departure Operational Concept. Center for Strategic and Budgetary Assessments, 2010.

U.S. DEPARTMENT OF DEFENSE. Military and Security Developments Involving the People's Republic of China 2010. Office of the Secretary of Defense. Department of Defense, 2010.

. Military and Security Developments Involving the People's Republic of China 2011. Office of the Secretary of Defense. Department of Defense, 2011.

VAN EVERA, Stephen. Guide to Methods for Students of Political Science. Ithaca: Cornell University Press, 1997. 
WALTZ, Kenneth. The Emerging Structure of International Politics. International Security, v. 18, n. 2, p. 44-79, 1993.

. Structural Realism after the Cold War. International Security, v. 25, n. 1, p. 5-41, 2000.

WOHLFORTH, Willian. The Stability of a Unipolar World. International Security, v. 24, n. 1, p. 5-41, 1999.

; BROOKS, Stephen. American Primacy in Perspective. Foreign Affairs, v. 81 , n. 4 , p. $20-33,2002$.

\section{Resumo}

\section{A Modernização Militar da China e a Distribuição de Poder no Leste Asiático}

Em razão do fim da União Soviética, China e Estados Unidos perderam um rival importante no Leste Asiático, o que alterou substancialmente a balança de poder da região, levando-a da multipolaridade à bipolaridade, ou seja, desde 1991 China e Estados Unidos são os únicos polos de poder na região. Para melhorar sua posição relativa nesta balança, o governo chinês vem investindo pesadamente na modernização de suas Forças Armadas. O tema deste estudo é o impacto da modernização militar chinesa sobre a distribuição de poder na região, considerando os inventários militares e seus meios de emprego (táticas assimétricas de antiacesso e negação de área), especialmente na esfera aeronaval. Isso nos leva ao problema geral da presente pesquisa: qual o impacto da modernização militar da China sobre a balança de poder do Leste Asiático? O método utilizado será o de estudo de caso - comparação focada e estruturada. Tal comparação terá um caráter sincrônico, ou seja, considerará os valores das variáveis em um dado momento, apenas. Conclui-se que a modernização militar do Exército de Libertação do Povo (ELP) mudou sensivelmente a distribuição de poder no Leste Asiático em favor da China.

Palavras-chave: Modernização Militar Chinesa - Estados Unidos - Leste Asiático - Balança de Poder 


\title{
Abstract
}

\section{China's Military Modernization and the Distribution of Power in East Asia}

\begin{abstract}
After Soviet Union's fall China and United States lost a dangerous foe in East Asia, and it changed enormously the balance of power in this region, transforming the multipolar distribution of power existing previously into a bipolar. In other words, since 1991 China and United states are the only great powers in East Asia. To improve its relative position in the balance of power, the Chinese government has invested substantially on modernizing its armed forces. The issue of this paper is the influence of the Chinese military modernization on regional balance of power, focusing especially in military inventories e its means of use (asymmetrical tactics of anti-access and area denial), mostly on maritime domain. It drives us to the central question of that research: what is the influence of Chinese military modernization on the distribution of power in East Asia. The method utilized is the case study - structured and focused comparison. The comparative has a synchronic approach, in other words are considered the values of variables in only one moment. One concludes that China's military modernization has changed substantially the balance of power in East Asia, favoring the Chinese position.
\end{abstract}

Keywords: Chinese Military Modernization - United States - East Asia Balance of Power 